\title{
Fundamental Issues in the Qualification of Smart and Intelligence in Building Materials Discourse: A Systematic Review
}

\author{
Ikechukwu Ogwu ${ }^{1, *} \mathbb{C}$, Zhilin Long ${ }^{1}$, Deuckhang Lee ${ }^{2}{ }^{\oplus}$, Xuhui Zhang ${ }^{1}$, Wei Zhang ${ }^{2}$ and Moses Okonkwo ${ }^{3}$ \\ 1 College of Civil Engineering and Mechanics, Xiangtan University, Xiangtan 411105, China; \\ longzl@xtu.edu.cn (Z.L.); xuhui.zhang@xtu.edu.cn (X.Z.) \\ 2 Department of Architectural Engineering, Chungbuk National University, Cheongju 28644, Korea; \\ dk@cbnu.ac.kr (D.L.); weizhangxtu@foxmail.com (W.Z.) \\ 3 Faculty of Environmental Science, Nnamdi Azikiwe University, Awka 420110, Nigeria; \\ mm.okonkwo@unizik.edu.ng \\ * Correspondence: ogwu@smail.xtu.edu.cn
}

Citation: Ogwu, I.; Long, Z.; Lee, D.; Zhang, X.; Zhang, W.; Okonkwo, M Fundamental Issues in the Qualification of Smart and Intelligence in Building Materials Discourse: A Systematic Review. Buildings 2021, 11, 558. https:// doi.org/10.3390/buildings11110558

Academic Editor: Umberto Berardi

Received: 12 October 2021

Accepted: 15 November 2021

Published: 18 November 2021

Publisher's Note: MDPI stays neutral with regard to jurisdictional claims in published maps and institutional affiliations.

Copyright: (c) 2021 by the authors. Licensee MDPI, Basel, Switzerland. This article is an open access article distributed under the terms and conditions of the Creative Commons Attribution (CC BY) license (https:// creativecommons.org/licenses/by/ $4.0 /)$.

\begin{abstract}
The fundamental notion of 'smart' in building materials discourse is responsiveness-the ability of materials to react to environmental stimuli by manifesting a noticeable physical change when there is a difference in the conditions of their immediate surroundings. This notion, however, is also interchanged with 'intelligence', which involves an array of control protocols. Notwithstanding, both notions are used synonymously and as occupant comfort and energy efficiency strategies in buildings. The current study aimed to underscore the fundamental issues in the conceptualization of both notions in building materials colloquy by systematic review of published literature following the Preferred Reporting Items for Systematic Reviews and Meta-Analyses (PRISMA) 2020 checklist. The review revealed that while smart responses are direct, predictable and reversible, requiring no external control system, computer systems and networks which require a constant supply of energy are essential for intelligence. In fact, the relationship between intelligent systems, energy efficiency and occupant comfort depends on external computer control and machine components of learning, resulting in complex systems with longer payback times, whereas smart materials and systems respond directly and immediately without additional energy or occupant control. The discussions present an attempt towards promoting zero additional energy demand for buildings using smart materials.
\end{abstract}

Keywords: energy; smart; intelligent; building materials; computer network; energy efficiency; zero additional energy; user control; occupant comfort; PRISMA 2020

\section{Introduction}

The primary notion of smart and smartness in building materials discourse is responsiveness - the ability of a material or system to react to (environmental) stimuli by manifesting a noticeable physical change when there is a difference in the conditions of its immediate surroundings [1-6]. Inspired by the need to find alternative solutions to the issue of energy consumption by exploring the properties of (building) materials, the notion provides an efficient means to manage energy in and around buildings [7-11], which has not changed since the energy crises of the 1970s and is still dependent on the combustion of fossil fuels. In fact, coal, oil and natural gas currently make up about $80 \%$ of today's energy use globally [12]. Energy, which is linked with all aspects of development and has a tremendous impact on the wellbeing of urban citizens' health, education, productivity, as well as economic opportunities, mainly comes from fossil-based sources [13], and the building industry, with its complex matrix of houses, factories, offices, schools, roads, bridges and parks, is one of the biggest consumers in the world, accounting for about $40 \%$ of energy consumption globally [14]. 
The resulting consequences of this combined with the increased awareness of climate change and other environmental concerns are empowering innovative solutions that seek to improve quality of life while being environmentally friendly. In fact, it is now possible to satisfy and eventually reduce the energy demands of buildings with less carbon-intensive approaches through advances in the realm of building physics, new technologies and materials science $[1,15]$, among which advances in materials would make the most impact since it has the most direct influence on buildings. Eight trends have been identified that are inspiring the new material science research directions $[6,8]$. They include:

1. Green materials (materials that can be reused with no adverse effect on the environment)

2. Fashion materials (materials developed for their aesthetic appeal)

3. Security materials (materials that provide increased resistance against storms/natural disasters as well as detection and alert systems)

4. Modern materials (referring to style genres-modern design, based on the use of new materials and processes)

5. Digital technology materials (materials aligned with technological fabrication processes otherwise difficult to realize)

6. Biomimicry (materials that imitate nature/natural processes)

7. Nanotechnology (materials used at atomic scale for industrial purposes)

8. Intelligent materials (materials that are responsive to external stimuli)

Intelligent materials have been described as being imbued with built-in sensors, actuators and control mechanisms able to detect stimuli, respond to it and then revert to its original state as soon as the stimuli is removed [16]. Intelligence has also been used in connection with buildings since the early 1980s, with the first definition given by the Intelligent Buildings Institute as "one which provides a productive and cost-effective environment through optimization of four basic elements: structure, systems, services and management, as well as the interrelationship between them" [17]. It uses computer technology to provide a more efficient environment by enhancing the connection between a building's form, flow, mechanical and electrical services, as well as its operation [18]. Thus, intelligent buildings adjust basic elements to meet user requirements using computer technology to make the communication between the elements possible. They are able to recognize stimuli (by acquiring information from the environment), discriminate (making good judgment by analyzing recognized stimuli), and then adjust accordingly (making regulated or controlled responses to stimuli received) $[19,20]$ by using computers and electronic technology systems. However, a common factor with all electronics, computer technology control systems, machines and any material with an electrical control need, is the provision of power. No matter how small, direct or distributed a component may be, electricity must still be supplied. If the device is made smaller, its power needs, in terms of both voltage and current, are reduced accordingly, but traditional power sources, which mostly come from fossil fuel combustion, cannot be correspondingly reduced [4].

With smart materials, however, the response ability to the received environmental stimuli is embedded in the material itself, requiring no external control system. Smart materials will exhibit the characteristics of immediacy (respond in real-time), transiency (respond to more than one environmental state), self-actuation (triggered discernment internal to, rather than external to, the material), selectivity (respond in distinct and predictable way), and directness (respond head-on to the stimuli) [21].

Indeed, while the responses of smart materials and systems come direct from the material itself and are reversible and predictable, it is practically impossible to have intelligence without (additional) computers and electronic technology (control) systems [3,22,23], which require a constant supply of energy, currently mainly sourced from the combustion of fossil fuels, which exacerbates climate change.

Both notions (of smart and intelligence) have also been combined in some instances as hybrid systems, with computer intelligence connected with smart materials to provide occupant comfort and efficient ways to manage energy. In fact, one of the first uses of the term "smart" in association with buildings was in connection with improved sensor- 
based monitoring and control systems for "intelligent" regulation of the indoor thermal environment of a house, which was imbued with computer intelligence along with miles of wiring and walls that concealed a household-wide skeleton of pipes to facilitate the distribution of data throughout the house [24].This hybrid system also promises to solve many of the issues associated with progressive urbanization, such as traffic congestion and strains on energy and water systems, amongst other things, through digitalization, with the use of computers and the internet. As a result, several highly innovative information technology companies, including IBM, Cisco, Telekom, Siemens, Toshiba, and Google, along with public utilities around the world, are actively investing in what has been termed "smart city development." Indeed, the socio-political requirements for energy management as a result of the energy crisis, and the possibility of interconnectivity within the internet of things (IOT) framework, are inspiring the transformation of urban centers into smart cities [25], and " ... technology enabling data capture and analysis, connectivity, monitoring and control is becoming the new baseline for smart buildings" [26]. However, as far as the preservation of energy and the conservation of the environment are concerned, computers and the associated infrastructure facilitating communications between them, are a huge part of the problem. Receiving, analyzing and processing data requires a great deal and constant supply of (additional) power. Buildings are already huge energy consumers. Why make a case for additional energy, only to justify its management and efficient use? Even if alternative energy is used to satisfy this 'additional' power, how much of it will be left to substitute current fossil fuel sources? Indeed, although information technology (IT) is transforming the way we create and interact with buildings, their energy, as well as associated operational requirements, cannot simply be overlooked.

\section{Materials and Methods}

The study developed a framework (shown in Figure 1) identifying two paths to comfort and energy efficiency in buildings. While there is a direct relationship in 'smart' between input-output, sensing-response, and external stimuli-action, with 'intelligence', the relationship between same variables is routed through computer control and monitoring systems which require energy that is mostly currently sourced from fossil fuel combustion. These inputs, including sensing and external stimuli, comprise environmental variables such as heat, moisture, light, electric/magnetic fields, or chemicals, which results in an output(response and action) that manifests in a color change, deformation, stiffness and viscosity change, potential difference, or emission of light. This framework suggests that it is possible to have responses to environmental stimuli without electrically controlled, computer-based and energy-dependent intelligence. Nonetheless, smart continues to be described as intelligence and vice versa, prompting the need for an investigation by systematic review of the available literature on the matter.

Systematic reviews use explicit and standardized approaches to collate and analyze the findings of studies that address a clearly structured question. The current study follows the PRISMA 2020 statement, which includes a flow diagram (see Figure 2) that has been developed to improve the transparent and complete reporting of (systematic) literature reviews [27].

The notions of smart and intelligence have been used interchangeably as synonyms to broadly describe energy efficiency and occupant comfort strategies. However, while smart responses are direct, requiring no external control, it is practically impossible to have intelligent responses without additional electronic technology control systems which require a constant supply of energy. The current study therefore aimed to establish the basic differences in the notions of smart and intelligence in building materials discourse, and attempts to make a case for 'smart' as a standalone notion for zero additional energy demand. 


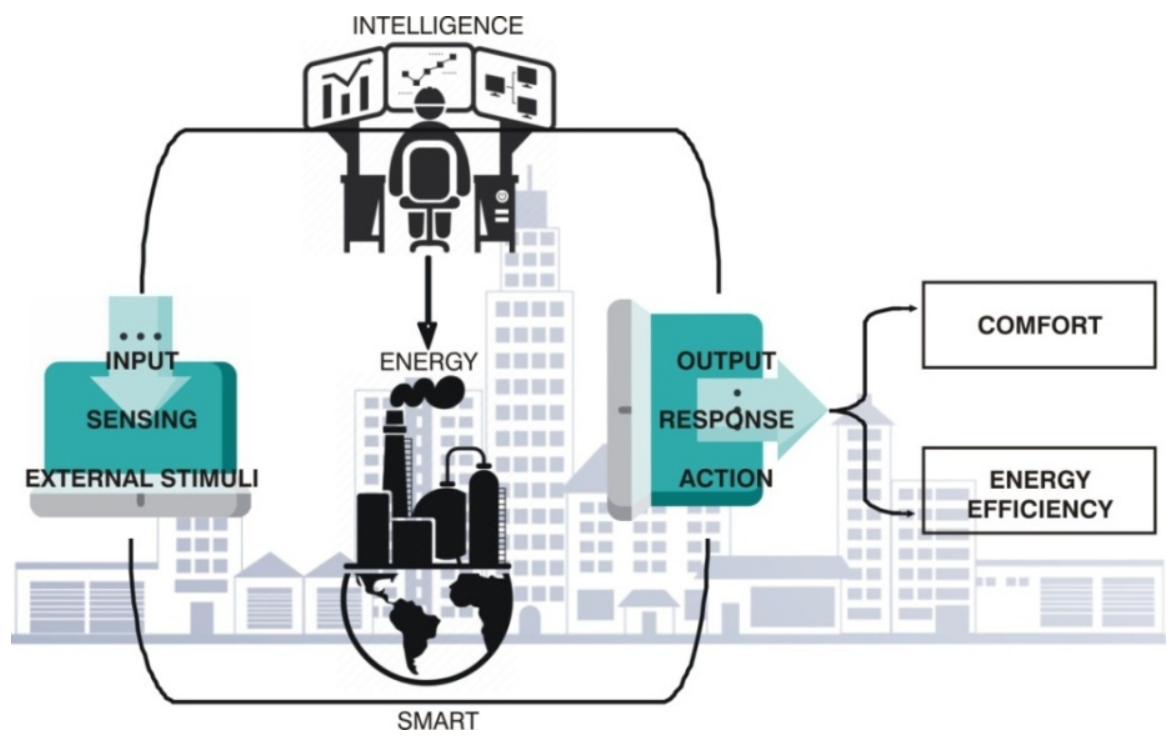

Figure 1. Conceptual framework (source: elaborated by the authors).

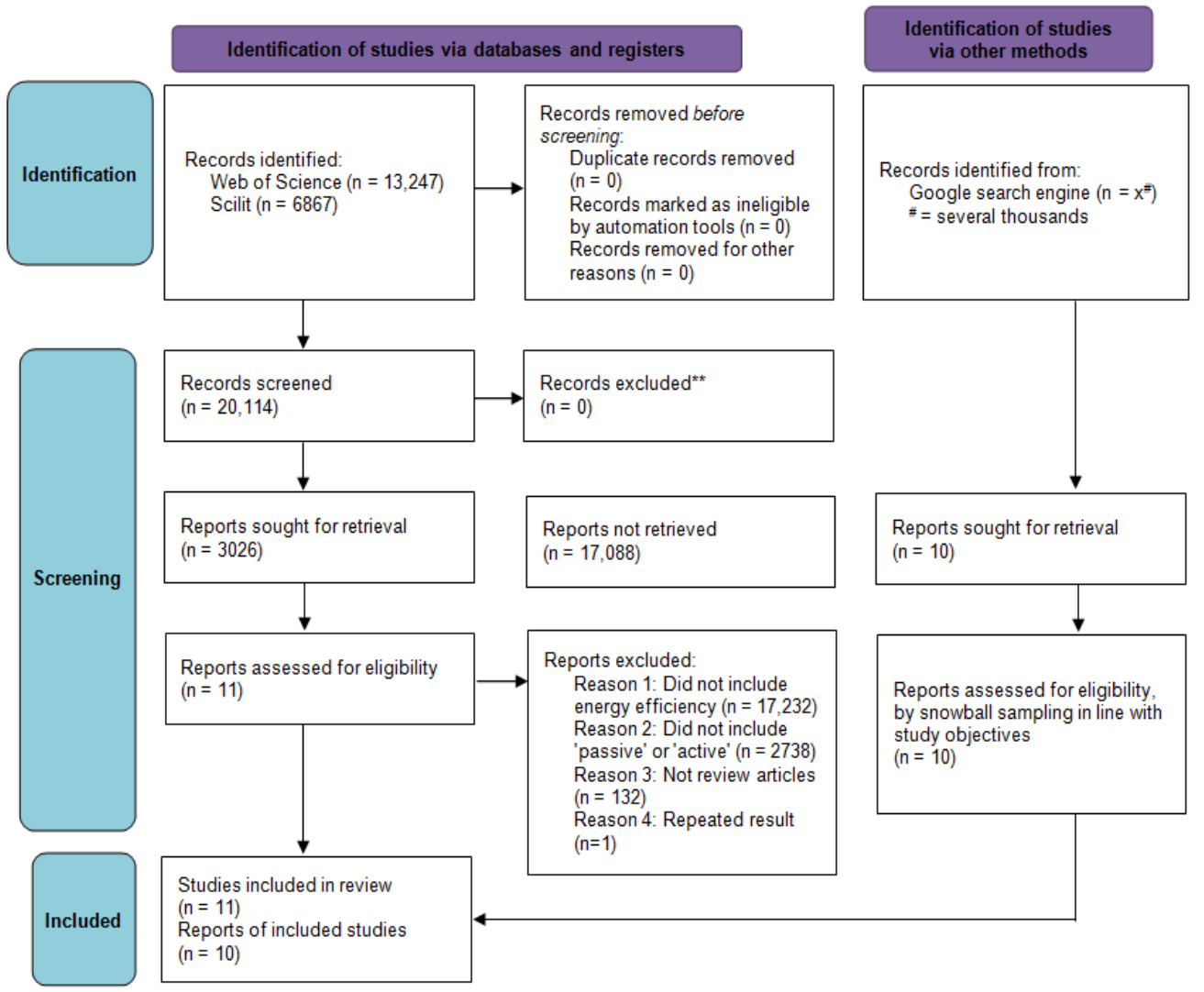

Figure 2. PRISMA 2020 flow diagram for new systematic reviews (adapted from Page et al., 2020 [27]).

For this systematic review, a search was conducted to identify academic publications on the existing state of affairs in the use of 'smart' and 'intelligence' in discussions around building materials. Independent queries were run in June 2021 on the Web of Science, Scilit, and Google search databases. The Web of Science database presents a rich collection of citation indexes, covering content including life sciences, biomedical sciences, engineering, social sciences, arts and humanities, natural sciences, health sciences, engineering, computer science, and materials sciences, representing the citation connections between 
scholarly research articles found in the most globally significant journals, books, and proceedings [28].

Scilit presents a multidisciplinary, free, and comprehensive database that indexes scientific material covering all subjects from arts and humanities, behavioral sciences, and social sciences to medicine and pharmacology, physical sciences, mathematics and computer science, chemistry, and biology by extracting the latest data from CrossRef, PubMed and other sources on a daily basis [29].

The selection of the articles was performed in multiple steps. The initial search was conducted in the Web of Science database for 'smart buildings', which resulted in a number of articles, $(\mathrm{n})=9038$. Because smart buildings contribute to energy savings, the search was refined with 'energy efficiency', resulting in $\mathrm{n}=1232$. Further, smart responses are direct, requiring no external control. They have also been described as 'passive'; thus, the search was refined accordingly, resulting in $n=47$. Based on the filter options provided on the database, 'review articles' were selected because they present a summary of the current state of understanding on a topic, resulting in $n=5$.

The same process was followed for 'intelligent buildings' on the Web of Science database, resulting in $n=4209$. Because intelligent buildings also contribute to energy savings, the search was refined with 'energy efficiency', resulting in $n=401$. Further, intelligent responses require external control. They have also been described as 'active'; thus, the search was refined accordingly, resulting in $n=28$. Based on the filter options provided by the database, 'review articles' were selected because they present a summary of the current state of understanding on a topic, resulting in $n=3$.

For Scilit, the same process was followed with independent queries for 'smart buildings' and 'intelligent buildings'.

For smart buildings, results revealed $n=4238$.

When refined with 'energy efficiency', $\mathrm{n}=965$.

Further refined with 'passive' resulted in $\mathrm{n}=34$.

The database presented no results for review articles; thus, $\mathrm{n}=0$.

For intelligent buildings, results revealed $\mathrm{n}=2629$.

When refined with 'energy efficiency', $\mathrm{n}=284$.

Further refinement with 'active' resulted in $\mathrm{n}=35$, and for review articles, $\mathrm{n}=3$.

Queries were also run on Google search engines at google.com. To ensure only standardized documents were returned, ".pdf" (portable document format) was included in the query. This returned documents that could be referenced and eliminated adverts. Publications were selected by exponential discriminative snowball sampling. Searches for 'smart buildings.pdf' and 'intelligent buildings.pdf' gave multiple referrals and were refined using the same criteria as the Web of Science and Scilit databases. However, final selection was based on the objective(s) of the study. A total of 10 articles were assessed as eligible for inclusion in the study. A summary is presented in Table 1 below.

Table 1. Summary of publication selection criteria.

\begin{tabular}{cccccc}
\hline \multirow{2}{*}{ Keywords/No. of Articles } & \multicolumn{2}{c}{ Web of Science Database } & \multicolumn{2}{c}{ Scilit Database } & Google \\
\cline { 2 - 6 } & Intelligence & Smart & Intelligence & Smart & Snowball Sampling \\
\hline Smart buildings & $\mathrm{n} / \mathrm{a}$ & 9038 & $\mathrm{n} / \mathrm{a}$ & 4238 & $\mathrm{n} / \mathrm{a}$ \\
Intelligent buildings & 4209 & $\mathrm{n} / \mathrm{a}$ & 2629 & 965 & 10 \\
Energy efficiency & 401 & 1232 & 284 & $\mathrm{n} / \mathrm{a}$ & \\
Active & 28 & $\mathrm{n} / \mathrm{a}$ & $\mathrm{n} / \mathrm{a}$ & 34 & 0 \\
Passive & $\mathrm{n} / \mathrm{a}$ & 47 & 3 & 21 & \\
Review & 3 & 5 & & & \\
TOTAL & & & &
\end{tabular}

Thus, 


$$
\begin{aligned}
\mathrm{n}_{\text {scilit (intelligence) }}+\mathrm{n}_{\text {scilit (smart) }} & =3+0=3 \\
\mathrm{n}_{\text {google (snowball sampling) }} & =10
\end{aligned}
$$

Total number of articles from the Web of Science and Scilit databases and Google search engine, i.e.,

$\mathrm{n}_{\text {web of science (intelligence) }}+\mathrm{n}_{\mathrm{web} \text { of science (smart) }+ \text { nscilit (intelligence) }}+\mathrm{n}_{\text {scilit (smart) }}+\mathrm{n}_{\text {google (snowball sampling) }}=21$

All queries were sent and returned in the English language. Additional data on the report (title, author/s, year, source/publisher, as well as the content of the study) were also obtained.

Efforts were made to eliminate bias in the current review study by running separate queries to identify articles on 'smart buildings' and 'intelligent buildings', as opposed to 'smart/intelligent buildings' or 'smart and intelligent buildings'. The study expectation notwithstanding, this was necessary to avoid results that already identify both notions as the same, unless the results of the review reveal so. This also ensured the focus of the query remained within the building materials range, eliminating 'materials' results from non-building fields. Examination and comparison of items was performed by tabulation, which provided easier and faster assessment of items in selected articles.

\section{Results}

A total of 21 articles (refined) were selected for review from three databases.

$\mathrm{n}_{\text {web of science (intelligence) }}+\mathrm{n}_{\mathrm{web} \text { of science (smart) }}+\mathrm{n}_{\text {scilit (intelligence) }}+\mathrm{n}_{\text {scilit (smart) }}+\mathrm{n}_{\text {google (snowball sampling) }}=21$

The full texts of each article were read and the contents analyzed. Each article was searched for statements associated with its aim, as well as identified energy efficiency and overall comfort strategy. Emerging issues with identified strategies was also highlighted against the energy efficiency/comfort strategy. A concise summary of the articles < $\mathrm{n}_{\text {web of science }}+\mathrm{n}_{\text {scilit }}>$ is presented in Table 2 below.

Analyzed content from Google snowball sampling [5-11] generally identifies smart and intelligence as synonyms and describes 'smart or intelligent buildings' as notions to ensure occupant comfort and energy savings. Notwithstanding, for Addington and Schodek [4], an attempt was made to distinguish between smart materials (which are able to respond to changes in the environment by generating a perceivable reaction), smart devices/systems (with embedded smart materials and computational enhancements able to respond to multiple stimuli), and intelligent components/environments (with interactive behaviors and controls that can 'act upon' the environment). However, in their proposed classification system of smart and intelligent materials and systems, intelligent components and environments usually consist of complex assemblies that combine traditional materials with smart materials and components, with resulting attributes enabled by computation (see Table 3). Now, these 'complex assemblies' and 'computation' involve computers and associated equipment that develop complex algorithms concerned with comfort or energy efficiency, while using energy which currently majorly comes from fossil fuel combustion, whereas smart materials manifest direct and reversible property change abilities in response to external stimuli. 
Table 2. Concise summary of articles from Web of Science and Scilit databases.

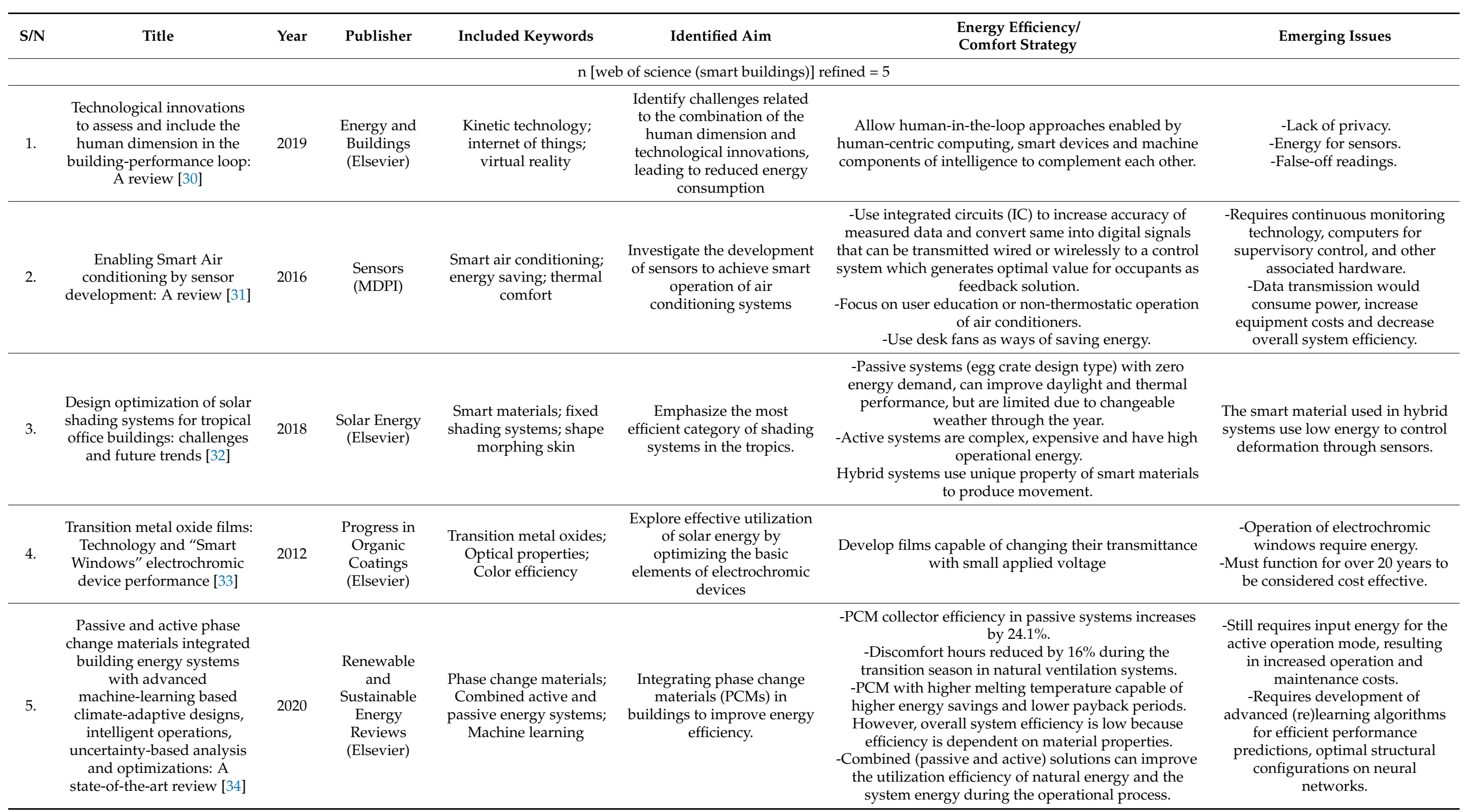


Table 2. Cont.

\begin{tabular}{|c|c|c|c|c|c|c|c|}
\hline $\mathrm{S} / \mathrm{N}$ & Title & Year & Publisher & Included Keywords & Identified Aim & $\begin{array}{l}\text { Energy Efficiency/ } \\
\text { Comfort Strategy }\end{array}$ & Emerging Issues \\
\hline \multicolumn{8}{|c|}{$\begin{array}{c}\mathrm{n} \text { [web of science (smart buildings)] refined }=5 \\
\mathrm{n} \text { [web of science (intelligent buildings)] refined }=3\end{array}$} \\
\hline 7. & $\begin{array}{l}\text { Active dynamic windows } \\
\text { for buildings: A review [36] }\end{array}$ & 2017 & $\begin{array}{l}\text { Renewable } \\
\text { Energy } \\
\text { (Elsevier) }\end{array}$ & $\begin{array}{c}\text { Smart windows; } \\
\text { electro-kinetic pixel } \\
\text { window; electrochromic } \\
\text { glazing }\end{array}$ & $\begin{array}{l}\text { Obtain a new generation of } \\
\text { advanced and transparent } \\
\text { windows, able to adapt to } \\
\text { environmental conditions, } \\
\text { ensuring efficient, } \\
\text { continuous and automatic } \\
\text { management of energy } \\
\text { relative to climate, user } \\
\text { behavior, and market } \\
\text { conditions of energy. }\end{array}$ & $\begin{array}{c}\text {-Passive systems respond independently to natural } \\
\text { environmental stimuli without any external induced } \\
\text { input. } \\
\text {-Installation is easy and reliable, but direct user control } \\
\text { according to occupant preference is not possible. } \\
\text {-Active systems respond to an external electrical } \\
\text { stimulus by changing their optical characteristics in } \\
\text { order to address user demands (they can be } \\
\text { self-powered by photovoltaic battery systems applied } \\
\text { to the window edge, without the need of power supply } \\
\text { wires and can be operated by smart phones, tablets via } \\
\text { Wi-Fi). }\end{array}$ & $\begin{array}{l}\text { Payback time for active systems in } \\
\text { both new residential and } \\
\text { commercial buildings is long. }\end{array}$ \\
\hline 8. & $\begin{array}{l}\text { The processing of optically } \\
\text { active functional } \\
\text { hierarchical nano-particles } \\
\text { [37] }\end{array}$ & 2016 & $\begin{array}{l}\text { Advanced } \\
\text { Powder } \\
\text { Technology } \\
\text { (Elsevier) }\end{array}$ & $\begin{array}{l}\text { Hierarchical structures; } \\
\text { yttrium } \\
\text { compound-based } \\
\text { phosphors; soft } \\
\text { chemical routes }\end{array}$ & $\begin{array}{l}\text { Develop new material forms } \\
\text { through controlled assembly } \\
\text { and hybridization of atoms } \\
\text { and molecules towards } \\
\text { desired functionality, low } \\
\text { carbon and sustainable } \\
\text { society. }\end{array}$ & $\begin{array}{l}\text { Future design of the advanced materials with multiple } \\
\text { functionalities able to respond to the emerging } \\
\text { environmental-energy problems in our society. }\end{array}$ & - \\
\hline \multicolumn{8}{|c|}{$\mathrm{n}$ [scilit (intelligent buildings)] refined $=3$} \\
\hline 9. & $\begin{array}{l}\text { Artificial Intelligence for } \\
\text { Efficient Thermal Comfort } \\
\text { Systems [38] }\end{array}$ & 2020 & $\begin{array}{l}\text { Frontiers in } \\
\text { Built } \\
\text { Environment }\end{array}$ & $\begin{array}{c}\text { Building energy } \\
\text { efficiency; intelligent } \\
\text { personal comfort } \\
\text { systems; machine } \\
\text { learning }\end{array}$ & $\begin{array}{l}\text { Explore the potential of } \\
\text { regulating thermal comfort } \\
\text { in occupied spaces by } \\
\text { improving functions of } \\
\text { operational devices. }\end{array}$ & $\begin{array}{l}\text { Integrate system of sensors to enable system } \\
\text { interoperability, learning and control algorithms, as } \\
\text { well as actuators working under a governing central } \\
\text { intelligent system, allowing for improvements in both } \\
\text { comfort and energy efficiency. }\end{array}$ & $\begin{array}{l}\text { Artificial intelligence (AI) systems } \\
\text { require an intelligent entity } \\
\text { (rational agent) and components } \\
\text { of the problem-solving process } \\
\text { (i.e., search algorithms, logic } \\
\text { inference, and machine learning). }\end{array}$ \\
\hline
\end{tabular}


Table 2. Cont

\begin{tabular}{|c|c|c|c|c|c|c|c|}
\hline $\mathrm{S} / \mathrm{N}$ & Title & Year & Publisher & Included Keywords & Identified Aim & $\begin{array}{l}\text { Energy Efficiency/ } \\
\text { Comfort Strategy }\end{array}$ & Emerging Issues \\
\hline \multicolumn{8}{|c|}{$\mathrm{n}$ [web of science (smart buildings)] refined $=5$} \\
\hline 10. & $\begin{array}{l}\text { A review on artificial } \\
\text { intelligence-based load } \\
\text { demand forecasting } \\
\text { techniques for smart grid } \\
\text { and buildings [39] }\end{array}$ & 2015 & $\begin{array}{c}\text { Renewable } \\
\text { and } \\
\text { sustainable } \\
\text { energy } \\
\text { reviews } \\
\text { (Elsevier) }\end{array}$ & $\begin{array}{l}\text { Artificial intelligence; } \\
\text { smart grid; neural } \\
\text { network }\end{array}$ & $\begin{array}{l}\text { Predict energy use pattern } \\
\text { for efficient energy } \\
\text { management planning. }\end{array}$ & $\begin{array}{l}\text { Use AI to predict energy use pattern for efficient energy } \\
\text { management planning. }\end{array}$ & $\begin{array}{l}\text {-Constant training/learning and } \\
\text { re-learning algorithms. } \\
\text {-Network complexities }\end{array}$ \\
\hline 11. & $\begin{array}{l}\text { Net zero energy building in } \\
\text { Brazil: Potential smart } \\
\text { building [40] }\end{array}$ & 2019 & IEEE & $\begin{array}{l}\text { Energy efficiency; Net } \\
\text { zero energy buildings; } \\
\text { smart buildings }\end{array}$ & $\begin{array}{c}\text { Establish correlation } \\
\text { between sustainable } \\
\text { buildings and smart } \\
\text { buildings. }\end{array}$ & $\begin{array}{l}\text { Extend the approach to sustainable, energy-efficient } \\
\text { buildings to include control and automation systems. }\end{array}$ & $\begin{array}{l}\text { Skepticism surrounding the } \\
\text { feasibility of Zero Energy } \\
\text { Buildings due to ever-increasing } \\
\text { energy demand, growing } \\
\text { population, decreasing } \\
\text { non-renewable energy resources, } \\
\text { energy pricing and climate change } \\
\text { issues. }\end{array}$ \\
\hline
\end{tabular}


Table 3. Proposed classification system for smart materials and intelligent components [41], adapted from Schwartz, 2002).

\begin{tabular}{|c|c|c|}
\hline Category & Material Characteristics & System Behavior \\
\hline \multicolumn{3}{|c|}{ Traditional materials } \\
\hline $\begin{array}{l}\text { Natural materials (stone, } \\
\text { wood) } \\
\text { Fabricated materials (steel, } \\
\text { aluminum, concrete) }\end{array}$ & $\begin{array}{l}\text { Materials have been given properties that } \\
\text { can be 'acted upon'. }\end{array}$ & $\begin{array}{c}\text { Materials have no inherent active response abilities } \\
\text { but have good performance properties. }\end{array}$ \\
\hline \multicolumn{3}{|c|}{ High performance/advanced materials } \\
\hline Polymers, composites & $\begin{array}{l}\text { Materials are designed for specific } \\
\text { purposes. }\end{array}$ & $\begin{array}{l}\text { Materials have limited inherent active response } \\
\text { abilities but have good performance properties. }\end{array}$ \\
\hline \multicolumn{3}{|c|}{ Smart materials } \\
\hline $\begin{array}{l}\text { Property-changing and } \\
\text { energy-exchanging materials }\end{array}$ & $\begin{array}{l}\text { Materials are designed to respond to } \\
\text { varying external conditions or stimuli. }\end{array}$ & $\begin{array}{l}\text { Materials have active responses to external stimuli } \\
\text { and can serve as sensors and actuators. }\end{array}$ \\
\hline \multicolumn{3}{|c|}{ Intelligent components } \\
\hline $\begin{array}{l}\text { Smart assemblies, polyvalent } \\
\text { walls }\end{array}$ & $\begin{array}{l}\text { Materials are designed to respond } \\
\text { intelligently to varying external } \\
\text { conditions in discrete locations. }\end{array}$ & $\begin{array}{l}\text { Complex behaviors can be designed to respond } \\
\text { intelligently and directly to multiple stimuli. }\end{array}$ \\
\hline \multicolumn{3}{|c|}{ Intelligent environments } \\
\hline & $\begin{array}{l}\text { Environments have designed interactive } \\
\text { behaviors with intelligent response } \\
\text { components that can 'act upon' the } \\
\text { environment. }\end{array}$ & $\begin{array}{l}\text { Intelligent environments consist of complex } \\
\text { assemblies that combine traditional materials with } \\
\text { smart materials and component whose interactive } \\
\text { characteristics are enabled by computation and } \\
\text { associated (computer) equipment. }\end{array}$ \\
\hline
\end{tabular}

\section{Discussion}

The current study sought to underscore the fundamental issue in the qualification of smart and intelligence in building materials discourse through systematic review of existing literature against the backdrop of energy efficiency and (occupant) comfort. The review revealed that the energy efficiency and comfort strategies concerned with intelligence involve machine components of learning and control algorithms, actuators working under a governing central intelligent system, an integrated system of sensors complementing each other, as well as integrated circuits to help increase the accuracy of measured data and convert the same into digital signals that can be transmitted wired or wirelessly to a control system. These control systems require the application of information and communication technology (ICT) to facilitate the implementation of advanced sensors and control algorithms. Thus, the measure of energy efficiency and comfort is largely dependent on the degree or level of automation and sophistication of the control system, which has also been described as complex and expensive, requiring high operational energy and a payback period, in some cases, of up to 20 years.

So-called 'hybrid systems' featuring human-in-the-loop approaches enabled by humancentric computing, smart devices and machine components of intelligence complementing each other have been suggested. However, the machine components still require continuous monitoring technology, computers for supervisory control, and other associated hardware, including data transmission systems, which would consume power, increase equipment costs and decrease the overall system efficiency. Consequently, systems with zero additional energy demand remain the best approach to the issue of energy use, and passive systems were identified as meeting these criteria, with smart materials able to respond independently to environmental stimuli without any external or induced input. Additionally, their installation is easy and reliable. However, direct user control according to occupant/user preference is not possible. Indeed, while smart/passive systems 
comprise advanced materials with multiple functionalities able to respond to the emerging environmental-energy problems in the society, it is practically impossible to have intelligent/hybrid/active systems without additional computer control and its resulting implications. Moreover, user control (an identified problem with smart systems), still presents a problem in intelligent systems, with some occupants still reporting feeling uncomfortable with the deployed optimized solutions, especially with mechanical heating, ventilation and air conditioning (HVAC). Studies reveal that as many as $43 \%$ of occupants are actually dissatisfied with mechanical HVAC, and $56 \%$ to $89 \%$ of government workers regard it as a problem in Europe and the US [42], and thus a mismatch between building systems and occupant comfort. Since energy savings in intelligent systems are largely determined by the degree of automation of the control system, and system performance depends on user behavior or acceptance, the personal preferences and requirements of each user would need to be taken more into account when optimizing control algorithms to achieve better system performance and thus higher energy savings. This, however, still presents a problem, because occupant behavior is not a precise and quantifiable science. Even with passive sensors (widely used because they are cheaper and consume less energy than active ones), an external power source is needed, 'false-off' readings may also occur frequently in systems as sensors may fail in detecting a stationary body, and so on [30]. Generally, now, building occupants actually accept a larger range of temperature variation in naturally ventilated buildings than in computer controlled air-conditioned ones [3].

\section{Conclusions}

The justification of this research work was in underscoring the fundamental issues in the conceptualization of the notions of 'smart' and 'intelligence' in building materials discourse against the backdrop of comfort and energy efficiency. The study reviewed published literature, following the PRISMA 2020 guidelines, from the Web of Science and Scilit databases. Additional articles and books were obtained from Google search by snowball sampling, and it was found that both notions were often used interchangeably even though they have distinct implications. On the one hand, while smart materials could be connected to computers to provide building occupants with control, the resulting intelligence, on the other, adds complexity to the system and ultimately increases the demand for energy. It has been argued that this 'additional energy' could be supplied from renewable sources. However, renewable energy systems still fall short because of their high upfront cost, intermittency and general low capacity. Additionally, sensor feedback is necessary to deploy comfortable solutions and energy savings in intelligent systems, but only after they have 'sensed' or detected all environmental variables. Monitoring, calculating, analyzing and transmitting all this data across a range of users with different needs would consume a lot of power, increase equipment as well as associated (installation) cost, and decrease the overall system efficiency. Consequently, until the global community finds more considerable alternatives, focus and attention should indeed be on zero energy demand technologies and systems.

Buildings remain the biggest energy consumers in the world, and thus present a huge opportunity for significant savings in global energy use, especially when the focus is shifted to address the issue from the point of demand. With smart materials, the requirement of zero additional energy demand and occupant comfort can be achieved without the need for computer-controlled intelligence. In fact, the current study revealed that while smart materials and systems independently manifest direct responses to external stimuli by altering their physical state and reverting back when the stimuli is removed, intelligent materials and systems provide occupant/user control of the environment and technological appeal, rather than comfort and energy efficiency. The prevalence of information and communication technology, interconnected devices and IOTs, enabled by even faster internet speeds, inadvertently positioned intelligent buildings as the next logical step in the evolution of buildings, and is now gradually expanding the current approach to building design to include automation and computer-based (control) systems, which will require machine 
learning and human-in-the-loop approaches with computers able to predict behavior and deploy solutions after close monitoring.

The world is experiencing an increase in energy demand. From energy use charts, energy use is on the increase, and this is largely due to the demand from electrically powered technologies that are presented as clean or efficient. The current study makes the case that focus should be on reducing or eliminating demand altogether with less pressure on existing sources of energy production. Thus, when assessing the key challenges of buildings in making them truly smart, the focus should be towards zero additional energy. Interventions in old and new buildings alike can come in the form of advanced, high-performance, passive smart materials that use their (material) properties to respond to the changes in their environment, resulting in significant energy savings by eliminating demand and ensuring overall occupant comfort. The approach to design and overall solutions to environmental problems should be region specific. Technology is not a onestop approach to issues, and the 'one size fits all' approach is no longer feasible. Instead of changing energy use, the focus should be on eliminating demand altogether. The properties of existing advanced smart materials with multiple functionalities can be further modified so they are able to respond to the emerging environmental-energy problems in our society.

Author Contributions: Conceptualization, I.O. and Z.L.; methodology, D.L.; software, I.O.; validation, I.O., X.Z. and W.Z.; formal analysis, W.Z.; investigation, M.O.; resources, Z.L.; data curation, M.O.; writing—original draft preparation, I.O.; writing—review and editing, I.O.; visualization, I.O.; supervision, Z.L.; project administration, D.L.; funding acquisition, Z.L. All authors have read and agreed to the published version of the manuscript.

Funding: This research received no external funding.

Conflicts of Interest: The authors declare no conflict of interest.

\section{References}

1. Ogwu, I.; Nzewi, N.U. Adopting the Principles of Building Physics, Smart Materials and New Technologies in the Design of Energy Efficient Buildings. Environ. Rev. J. Fac. Environ. Sci. 2017, 6, 1-9. Available online: http://erjournal.net/index.php/ erjournal/article/view/30/pdf1 (accessed on 21 June 2021).

2. Ikechukwu, O.; Moses, O. Conceptual Issues in the Qualification of Intelligent Buildings. Open J. Energy Effic. 2019, 8, 52-63. [CrossRef]

3. Ogwu, I.; Long, Z.; Okonkwo, M. Issues in the Conceptualization and Understanding of Intelligent Buildings. In New Ideas Concerning Science and Technology; Adnan, S.H.B., Ed.; SCIENCE Domain International: London, UK, 2020 ; Volume 1, pp. 12-21. [CrossRef]

4. Addington, M.; Schodek, D. Smart Materials and New Technologies: For the Architecture and Design Professions; Architectural Press: Burlington, MA, USA, 2005; pp. 21-95.

5. Christopher, O.O. Chemical Indicating Devices. In Encyclopedia of Smart Materials (1 E 2); Schwartz, M., Ed.; John Wiley \& Sons Inc.: Hoboken, NJ, USA, 2002; pp. 173-182.

6. Bell, J.M.; Skryabin, I.L.; Matthews, J.P. Windows. In Encyclopedia of Smart Materials (1 \& 2); Schwartz, M., Ed.; John Wiley \& Sons Inc.: Hoboken, NJ, USA, 2002; pp. 1134-1145.

7. Bax, L.; Cruxent, J.; Komornicki, J. Key to Innovation Integrated Solution: Innovative Chemistry for Energy Efficiency of Buildings in Smart Cities, SusChem-European Technology Platform for Sustainable Chemistry, European Commission Smart Cities Stakeholder Platform; The European Chemical Industry Council: Brussels, Belgium, 2019; pp. 8-12. Available online: https://cefic.org/app/uploads/ 2019/01/Innovative-Chemistry-for-Energy-Efficiency-of-Buildings-in-SmartCities-BROCHURE-iNNOVATION.pdf (accessed on 21 June 2021).

8. Gomaa, E.G.; Badran, E.E.; Mahmoud, M.A.; Saleh, A.M. The Use of Smart Materials in raising the Efficiency Performance of Buildings. Int. J. Appl. Innov. Eng. Manag. 2016, 5, 1-18.

9. Makakli, E.S. Potential of Smart Materials for Sustainable Architecture. Int. J. Soc. Sci. 2016, 55, 267-275. [CrossRef]

10. Nitesh, D.; Ashish, C. Smart Construction Materials \& Techniques AICMT. In Proceedings of the National Conference on Alternative \& Innovation Construction Materials \& Techniques TEQIP-II/Civil/AICMT-3; e-Proceeding: MITS under TEQIP-II, Gwalior, India, August 2014. Available online: https://www.researchgate.net/publication/297167802_SMART_CONSTRUCTION_ MATERIALS_TECHNIQUES (accessed on 20 June 2021).

11. Federiac, R.; Fabiani, C.; Chiatti, C.; Pisello, A.L. Cool, Photoluminescent Paints towards Energy Consumption Reductions in the Built Environment. J. Phys. Conf. Ser. 2019, 1343, 012198. [CrossRef]

12. ExxonMobil. Outlook for Energy: A Perspective to 2040; ExxonMobil Corporation: Irving, TX, USA, 2019; pp. 7-12. 
13. Cristian, G.; Christian, I.; Energy and Environmental Issues in Smart Buildings. CiteSeerx 2019, 26-51. Available online: https: / / citeseerx.ist.psu.edu/viewdoc/download?doi=10.1.1.582.2152\&rep=rep1\&type=pdf (accessed on 6 July 2021).

14. World Business Council for Sustainable Development-WBCSD. Communicating Collective and Individual Climate-Related Challenges and Action; Construction and Building Materials; TCFD Preparer Forum: Geneva, Switzerland, 2020; pp. 7-15. Available online: https:/ / www.wbcsd.org/Programs/Redefining-Value/TCFD/Resources/Construction-and-Building-Materials-shareTCFD-implementation-experience (accessed on 20 March 2021).

15. Hens, S.L.; Hugo, C. Applied Building Physics: Ambient Conditions, Building Performance and Material Properties, 2nd ed.; Wilhelm Ernst \& SohnVerlag für Architektur und technische Wissenschaften GmbH \& Co. KG: Berlin, Germany, 2016; pp. 1-7.

16. Arvind, K.; Ajay, V.; Rawat, R.S.S. Intelligent Material for Modern Age: A Review. IOSR J. Mech. Civ. Eng. 2016, 13, 10-15. [CrossRef]

17. Commscope. Available online: https://www.commscope.com/Blog/Defining-Todays-Intelligent-Building (accessed on 27 June 2021).

18. Caffrey, R. The Intelligent Building-An ASHRAE Opportunity. ASHRAE Tech. Data Bull. 1985, 94, $2-7$.

19. Toshinori, T. A Concept of Intelligent Materials. J. Intell. Mater. Struct. 1990, 1, 149-156. [CrossRef]

20. Mohamed, A.S.Y. Smart Materials Innovative Technologies in Architecture: Towards Innovative Design Paradigm. Energy Procedia 2017, 115, 139-154. [CrossRef]

21. Moulaii, M.; Mahdavinejad, M.; Gheisar, M. The status of energy efficient usage of smart materials in sustainable built environment in hot and dry climates (case study: Middle Eastern countries). In Proceedings of the International Conference on Intelligent Building and Management, Proc. of CSIT (5), Singapore, 16-18 September 2011; IACSIT Press: Singapore, 2011 ; pp. 340-345.

22. Schlangen, E.; Joseph, C. Self-healing Processes in Concrete. In Self-healing Materials: Fundamentals, Design Strategies and Applications; Ghosh, S.K., Ed.; Wiley-VCH: Weinheim, Germany, 2009; pp. 141-179.

23. Stimmel, L. Carol. Building Smart Cities: Analytics, ICT, and Design Thinking; CRC Press: Boca Raton, FL, USA, 2016 ; pp. 6-46.

24. The Washington Post. Available online: https:/ /www.washingtonpost.com/archive/realestate/1990/11/03/smart-homes-waveof-the-90s /5d69abfe-b115-4edb-92da-5af81699d05f/?utm_term=.6eba30f49602 (accessed on 20 June 2021).

25. Gassmann, O.; Böhm, J.; Palmié, M. Smart Cities: Introducing Digital Innovation to Cities, 1st ed.; Emerald Publishing Limited, Howard House: Bingley, UK, 2019; pp. 5-65.

26. SIEMENS. Smart buildings: New Criteria for a New, Smart Building Era; Article no. SI_0183_EN (Status 11/2019); Smart Infrastructure Global Headquarters; Siemens Switzerland Ltd.: Zug, Switzerland, 2019; Volume 2.

27. Page, M.J.; Moher, D.; Bossuyt, P.M.; Boutron, I.; Hoffmann, T.C.; Mulrow, C.D.; Shamseer, L.; Tetzlaff, J.M.; Akl, E.A.; Brennan, S.E.; et al. PRISMA 2020: Explanation and Elaboration: Updated guidance and exemplars for reporting systematic reviews. BMJ 2021, 372, n160. [CrossRef] [PubMed]

28. Clarivate: Accelerating Innovation. Available online: https://clarivate.libguides.com/webofscienceplatform/coverage (accessed on 20 June 2021).

29. Scilit-A Comprehensive, Open-Access Scholarly Database. Available online: https://blog.mdpi.com/2017/11/24/scilitcomprehensive-database/ (accessed on 20 June 2021).

30. Bavaresco, M.V.; D'Oca, S.; Ghisi, E.; Lamberts, R. Technological innovations to assess and include the human dimension in the building-performance loop: A review. Energy Build. 2019, 202, 109365. [CrossRef]

31. Cheng, C.; Lee, D. Enabling smart air conditioning by sensor development: A Review. Sensors 2016, 16, 2028. [CrossRef]

32. Al-Masrani, S.M.; Al-Obaidi, K.M.; Zalin, N.A.; Isma, M.A. Design optimization of solar shading systems for tropical office buildings: Challenges and future trends. Sol. Energy 2018, 170, 849-872. [CrossRef]

33. Gesheva, K.A.; Ivanova, T.M.; Bodurov, G. Transition metal oxide films: Technology and "Smart Windows" electrochromic device performance. Prog. Org. Coat. 2012, 74, 635-639. [CrossRef]

34. Zhou, Y.; Zheng, S.; Liu, Z.; Wen, T.; Ding, Z.; Yan, J.; Zhang, G. Passive and active phase change materials integrated building energy systems with advanced machine-learning based climate-adaptive designs, intelligent operations, uncertainty-based analysis and optimizations: A state-of-the-art review. Renew. Sustain. Energy Rev. 2020, 130, 109889. [CrossRef]

35. Plörer, D.; Hammes, S.; Hauer, M.; van Karsbergen, V.; Pfluger, R. Control Strategies for Daylight and Artificial Lighting in Office Buildings-A Bibliometrically Assisted Review. Energies 2021, 14, 3852. [CrossRef]

36. Casini, M. Active dynamic windows for buildings: A review. Renewable Energy 2017, 119, 923-934. [CrossRef]

37. Mancic, L.; Nikolic, M.; Gomez, L.; Rabanal, M.E.; Milosevic, O. The processing of optically active functional hierarchical nanoparticles. Adv. Powder Technol. 2016, 28, 3-22. [CrossRef]

38. Ghahramani, A.; Galicia, P.; Lehrer, D.; Varghese, Z.; Wang, Z.; Pandit, Y. Artificial Intelligence for Efficient Thermal Comfort Systems: Requirements, Current Applications and Future Directions. Front. Built Environ. 2020, 6, 1-16. [CrossRef]

39. Raza, M.Q.; Khosravi, A. A review on artificial intelligence based load demand forecasting techniques for smart grid and buildings. Renew. Sustain. Energy Rev. 2015, 50, 1352-1372. [CrossRef]

40. Silva, R.D.D.E.; de Oliveira, R.C. Net Zero Energy Building in Brazil: Potential Smart Buildings? In Proceedings of the IEEE PES Innovative Smart Grid Technologies Conference, Latin America (ISGT Latin America), Gramado, Brazil, 15-18 September 2019. [CrossRef] 
41. Nasr, Y.T.A. Using Smart Materials to Mimic Nature in Architecture. Master's Thesis, Graduate School, Faculty of Engineering, Alexandria University, Alexandria, Egypt, 19 April 2017.

42. Francis, A.; Cristian, G. Natural Ventilation in the Urban Environment. In Building Ventilation: The State of the Art; Santamouris, M., Wouters, P., Eds.; Earthscan: London, UK, 2006; pp. 1-35. 